\title{
Thymol exerts anti-inflammatory effect in dextran sulfate sodium-induced experimental murine colitis
}

\author{
De-Ming Liu ${ }^{1}$, Chun-Yan Zhou ${ }^{2}$, Xian-Li Meng ${ }^{1}$, Ping Wang ${ }^{1}$, Wen Li $^{1 *}$ \\ ${ }^{1}$ School of Pharmacy, Chengdu University of Traditional Chinese Medicine, Chengdu 610037, ${ }^{2}$ School of Nursing, North \\ Sichuan Medical College, Nanchong 637300, China
}

*For correspondence: Email: wenlitcm@163.com; Tel: +86-28-87786551

\begin{abstract}
Purpose: To investigate the effect of thymol on dextran sulfate sodium (DSS)-induced experimental colitis in mice.

Methods: Colitis in mice was induced by drinking water with $2.5 \%(w / v)$ DSS. The levels of myeloperoxidase (MPO), malondialdehyde (MDA), glutathione (GSH) and superoxide (SOD) in colonic tissues were determined using commercial kits. Histological changes were evaluated by hematoxylin and eosin staining. The production of nitric oxide (NO) was measured by Griess assay. The levels of pro-inflammatory cytokines including TNF- $\alpha, I L-1 \beta$ and IL- 6 were assessed by quantitative PCR and ELISA kits. Nuclear factor-kappaB (NF-kB) pathway activation was determined by Western blot.

Results: Thymol markedly reduced disease activity index (DAI) scores, and recovered the colon length. Histological damage and MPO levels in the colonic tissues were markedly inhibited $(p<0.05)$ by thymol, which also reduced mRNA expressions of TNF- $\alpha, I L-1 \beta$ and IL-6 in the colon. In addition, it downregulated MDA level but elevated GSH and SOD levels. Moreover, in vitro data showed that thymol significantly inhibited $(p<0.05)$ lipopolysaccharide-induced secretion of NO, TNF- $\alpha, I L-1 \beta$ and IL-6 in macrophages, and suppressed $(p<0.05)$ the activation of NF-KB pathway.

Conclusion: Thymol attenuates experimental colitis by down-regulating the activation of NF-KB pathway. Therefore, thymol is a potential candidate drug for the management of ulcerative colitis.
\end{abstract}

Keywords: Thymol, Ulcerative colitis, Dextran sulfate sodium, Macrophages, Nuclear factor-kappaB

\begin{abstract}
This is an Open Access article that uses a funding model which does not charge readers or their institutions for access and distributed under the terms of the Creative Commons Attribution License (http://creativecommons.org/licenses/by/4.0) and the Budapest Open Access Initiative (http://www.budapestopenaccessinitiative.org/read), which permit unrestricted use, distribution, and reproduction in any medium, provided the original work is properly credited.

Tropical Journal of Pharmaceutical Research is indexed by Science Citation Index (SciSearch), Scopus, International Pharmaceutical Abstract, Chemical Abstracts, Embase, Index Copernicus, EBSCO, African Index Medicus, JournalSeek, Journal Citation Reports/Science Edition, Directory of Open Access Journals (DOAJ), African Journal Online, Bioline International, Open-J-Gate and Pharmacy Abstracts
\end{abstract}

\section{INTRODUCTION}

Ulcerative colitis (UC) is a chronic inflammatory disorder in the colon, which not only harms the life quality of patients, but elevates the probability of colorectal cancer [1,2]. The precise cause of UC is poorly understood. However, bowel inflammation could be elicited by dysregulated immune response to commensal gut flora in individuals with genetic susceptibility [3]. Dextran sulfate sodium (DSS)-induced colitis in mice has been extensively applied for UC study, which is characterized by many symptoms mimic some clinical features in human UC such as body weight loss, diarrhea, blood in stool and mucosal ulceration [4].

Traditional therapies of UC are 5- 
aminosalicylates (5-ASA) and corticosteroids, which mainly focus on the reduction of the inflammatory response and abnormal immune responses. However, adverse effects such as diarrhea, cramps, fever, rash and kidney problems are associated with 5-ASA administration. In addition, some immune modulators like azathioprine are also used in the treatment of UC patients, but accompanied by severe adverse events or poor therapeutic effects $[5,6]$. Thus, it is necessary to develop more effective therapeutic modalities that attenuate the colonic inflammation.

Thymol, a natural monoterpene compound, is one of the active components of Chinese herb Thymus vulgaris, and the constituent of other plants such as Monarda punctate and Origanum vulgare spp [7]. Previous studies showed that thymol had various bioactivities, such as antiinflammatory [8,9], anti-bacterial [10], anticancer and antioxidant properties [11]. Although thymol had wide-ranging pharmacological actions, the anti-inflammatory ability of thymol on experimental colitis has not been studied. The present study was to investigate the effect of thymol on DSS-induced colitis in mice. The mechanisms of how the thymol inhibits oxidative stress, pro-inflammatory mediator's production and NF-KB signaling pathway were explored.

\section{EXPERIMENTAL}

\section{Chemicals and reagents}

Thymol (> $98 \%$ purity) and lipopolysaccharide (LPS, B5) were purchased from Sigma (St. Louis, USA). Dextran sulfate sodium (DSS, 36000-50000 Da) was obtained from MP Bio (Aurora, USA). HiScript Q RT SuperMix and AceQ qPCR SYBR Green Master Mix were from Vazyme Biotech (Nanjing, China); Antibodies with phosphorylation of $1 \mathrm{kB} \alpha, \mathrm{NF}-\mathrm{kB}-\mathrm{p} 65$ and GAPDH were obtained from Bioworld Biotech (Nanjing, China). ELISA kits for mouse TNF-a, IL-6 and IL-1 $\beta$ were obtained from Dakewe Biotech (Shenzhen, China). Malondialdehyde (MDA), glutathione (GSH), superoxide (SOD) and myeloperoxidase (MPO) assay kits were products of Nanjing JianCheng Bioengineering Institute (Nanjing, China). MTT and TRIzol were obtained from Invitrogen (Carlsbad, USA).

\section{Animals}

Male C57BL/6 mice, 6-8 weeks old, were used (Beijing Vital River Laboratory Animal Tech, Beijing, China). The study protocol was approved by the Ethics Committee of Chengdu University of Traditional Chinese Medicine (no. 2014 DL-
023) in accordance to "Principles of Laboratory Animal Care" (NIH publication no. 85-23, revised 1985) [12].

\section{Colitis induction}

DSS-induced colitis was performed as described previously [13]. Mice were randomly assigned into five groups: normal, model, thymol (30 $\mathrm{mg} / \mathrm{kg}$ ), thymol $(60 \mathrm{mg} / \mathrm{kg}$ ) and 5-ASA (100 $\mathrm{mg} / \mathrm{kg}$ ). In addition to mice in normal group, other mice were provided with drinking water with 2.5 $\%(w / v)$ DSS for seven days ad libitum, from day 0 to day 6 , and then with water from day 7 to day 9. Thymol $(30,60 \mathrm{mg} / \mathrm{kg})$ and $5-A S A(100 \mathrm{mg} / \mathrm{kg})$ were orally administered for 10 consecutive days, from day 0 to day 9 .

The mice were observed and recorded daily for body weight, diarrhea and gross bleeding in feces. Disease activity index (DAl) score $=$ (body weight + diarrhea + gross bleeding) / 3 [14]. Mice were euthanized by $\mathrm{CO}_{2}$ inhalation at day 9 after DSS induction. The colon was harvested and the length was determined.

\section{Histological assessment}

The colon tissues were fixed in paraformaldehyde and further embedded in paraffin. Then, the slides of colon tissues stained with hematoxylin and eosin. Histological score was carried out by analyzing the inflammation severity, inflammation extent and crypt damage as previously described [15].

\section{Evaluation of MDA, GSH, SOD and MPO}

Levels of MDA, GSH, SOD and MPO in colon homogenate were determined according to the manufacturer's protocol. Total protein was measured by a bicinchoninic acid protein kit (Beyotime Biotech, Shanghai, China).

\section{Real-time PCR analysis}

Total RNA was extracted from colon tissue using TRIzol reagent and reverse transcribed to cDNA. The mRNA expression were performed on a CFX96 Real-time PCR Detection System (Biorad) according to the instructions of HiScript $Q$ RT SuperMix and AceQ qPCR SYBR Green Master Mix. The primer sequences are listed in Table 1. The expression of GAPDH was used for the normalization.

\section{Cell culture}

RAW 264.7 cells were obtained from Shanghai Institute of Cell Biology (Shanghai, China). RAW 
Table 1: Prime sequences of target genes

\begin{tabular}{lll}
\hline Target gene & Forward & Reverse \\
\hline TNF- $\alpha$ & ACC CTC ACA CTC ACA AAC CA & ATA GCA AAT CGG CTG ACG GT \\
IL-6 & CCC AAT TTC CAA TGC TCT CCT & AAC GCA CTA GGT TTG CCG A \\
IL-1 $\beta$ & TGC CAC CTT TTG ACA GTG ATG & AAG GTC CAC GGG AAA GAC AC \\
GAPDH & TCA GGA GAG TGT TTC CTC GT & TTC CCA TTC TCG GCC TTG AC \\
\hline
\end{tabular}

264.7 cells were cultured in DMEM medium (Gibco, Carlsbad, USA) with fetal bovine serum (10\%), penicillin (100 U/mL), and streptomycin (100 $\mathrm{\mu g} / \mathrm{mL})$ under a normal $\left(37^{\circ} \mathrm{C}, 5 \% \mathrm{CO}_{2}\right)$ humidified air.

RAW 264.7 cell growth was measured by MTT assay. RAW 264.7 cells were plated in 96-well plate at a density of $2 \times 10^{5}$ cells per well, and stimulated with various concentrations of thymol $(0,25,50,100,200$ and $400 \mu \mathrm{M})$, with or without $1 \mu \mathrm{g} / \mathrm{mL}$ LPS for $20 \mathrm{~h}$ [16]. Cell viability was measured absorbance at $570 \mathrm{~nm}$ using a microplate reader.

\section{Measurement of nitric oxide (NO) and cytokines}

RAW 264.7 cells were plated in 96-well plate at a density of $2 \times 10^{5}$ cells per well, and stimulated with $1 \mu \mathrm{g} / \mathrm{mL}$ LPS in the presence of thymol $(50$, 100 and $200 \mu \mathrm{M}$ ) for $24 \mathrm{~h}$. NO level in supernatant was evaluated as described before [17]. The absorbance at $550 \mathrm{~nm}$ was measured using a microplate reader (Thermo). According to the manufacture's protocol, the levels of TNF- $\alpha$, IL-6 and IL-1 $\beta$ in cell supernatant were determined using specific ELISA kits.

\section{Western blot assay}

Cells $\left(1 \times 10^{6}\right.$ cells $\left./ \mathrm{mL}\right)$ were pretreated with thymol $(50,100$ and $200 \mu \mathrm{M})$ for $20 \mathrm{~h}$, and further cultured with $1 \mu \mathrm{g} / \mathrm{mL}$ LPS for another 30 min. Total proteins were extracted using RIPA lysis buffer and loaded onto a $10 \%$ SDS-PAGE. Blots transferred onto a polyvinylidene fluoride membrane (Millipore, Bedford, USA). The primary antibodies used in this study including $\mathrm{p}$ IKBa (1:1000), p-NF-KB-p65 (1:1000), and GAPDH (1:5000). The signals were measured using the Western HRP substrate (Bio-rad).

\section{Statistical analysis}

Data are shown as mean \pm SEM. One-way ANOVA followed by Dunnett's test were used to determine the level of significance, and $p<0.05$ was considered statistically significant. The data were analyzed using GraphPad Prism 5 (La Jolla, USA).

\section{RESULTS \\ Effect of thymol on colitis}

To determine the effect of thymol on experimental colitis, colitis was induced by adding DSS into drinking water in mice. DSS markedly induced DAI elevation in mice. Thymol $(60 \mathrm{mg} / \mathrm{kg})$ as well as 5-ASA decreased the DAI score when compared to the DSS group (Figure $1 \mathrm{~A})$. Figure $1 \mathrm{~B}$ shows that thymol $(60 \mathrm{mg} / \mathrm{kg})$ significantly recovered the colon length when compared with the DSS group, so as 5-ASA did. Figure $1 \mathrm{C}$ shows that the activities of MPO in colons were also decreased in thymol $(60 \mathrm{mg} / \mathrm{kg})$ and 5-ASA.

\section{Effect of thymol on colonic pathological changes}

Histological analysis of colons from DSS-induced mice demonstrated severe damage to the epithelium, goblet cells lost, inflammatory cells infiltration, and severe damages in mucosal and submucosal. However, these pathological changes were much attenuated by thymol (60 $\mathrm{mg} / \mathrm{kg}$ ) and 5-ASA (Figure 2A). The histological scores of each group were shown in Figure 2B.

\section{Effect of thymol on the production of pro- inflammatory cytokines in colons}

To analyze the effect of thymol on the proinflammatory cytokines involved in the induction of UC, the mRNA expressions of TNF- $\alpha$, IL- 6 and IL-1 $\beta$ in colon tissues were determined by realtime PCR. In DSS group, the mRNA expressions of TNF- $\alpha$, IL- 6 and IL-1 $\beta$ were markedly increased when compared with normal group. Thymol $(60 \mathrm{mg} / \mathrm{kg})$ and 5-ASA treatments significantly reduced the level of TNF- $\alpha$, IL- 6 and $\mathrm{IL}-1 \beta$ in colon tissues (Figure $3 \mathrm{~A}-\mathrm{C}$ ).

\section{Effect of thymol on oxidative stress in colon tissues}

To determine the effect of thymol on oxidative stress involving in the inflammatory response and intestinal damage, the levels of MDA, GSH and SOD in colon tissues were measured. The DSS administration increased MDA level, decreased levels of GSH and SOD in colon tissues. However, thymol $(60 \mathrm{mg} / \mathrm{kg})$ treatment 
A

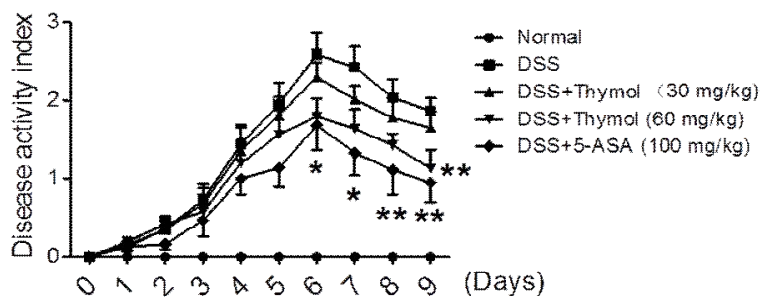

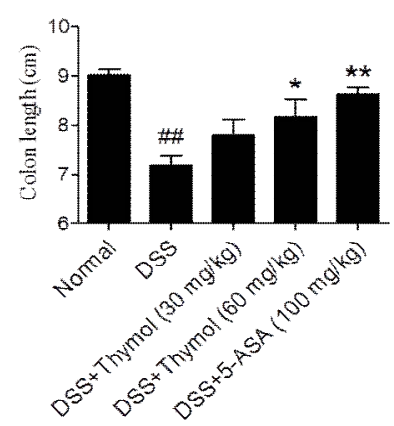

$\mathrm{C}$

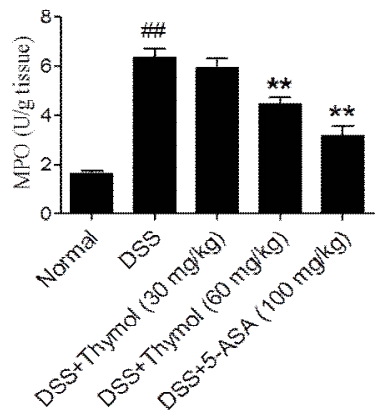

Figure 1: Effect of thymol on murine colitis. (A) DAl scores; (B) colon length; (C) MPO activity in colon tissues ( $n$ = 6). ${ }^{\# \#} p<0.01$ vs normal, ${ }^{*} p<0.05,{ }^{* *} p<0.01$ vs DSS

$A$

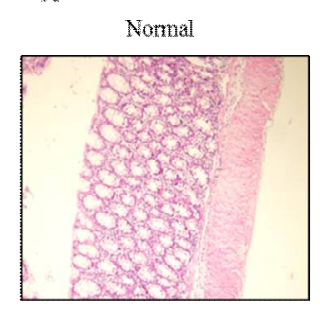

$\mathrm{Dss}+$ Thymol $(60 \mathrm{mg} / \mathrm{kg})$

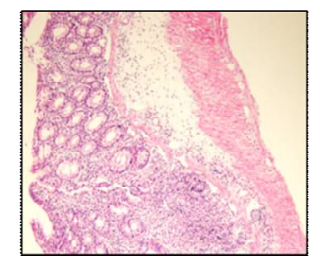

DSS

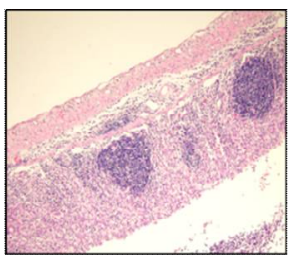

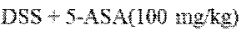

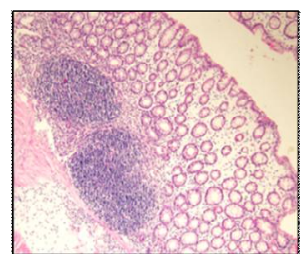

b

DSS + Thwol ( $30 \mathrm{mg} \mathrm{kg})$
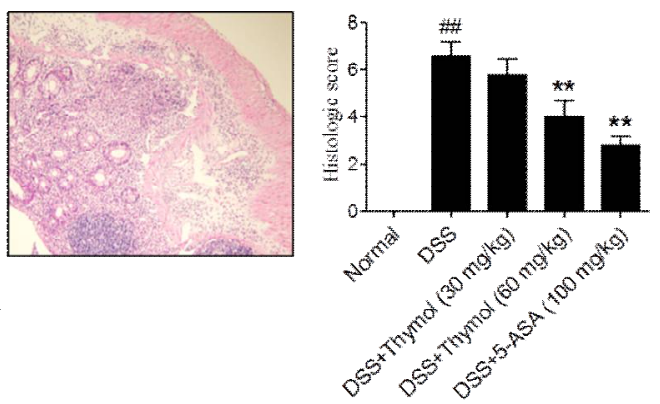

Figure 2: Effect of thymol on the histological changes. (A) Histological changes in colon tissues. The original scale was 200 micrometer. (B) Histological scores from each group $(n=6) .{ }^{\# \#} p<0.01$ vs normal, ${ }^{\star} p<0.05$, ${ }^{\star \star} p<$ 0.01 vs DSS

A

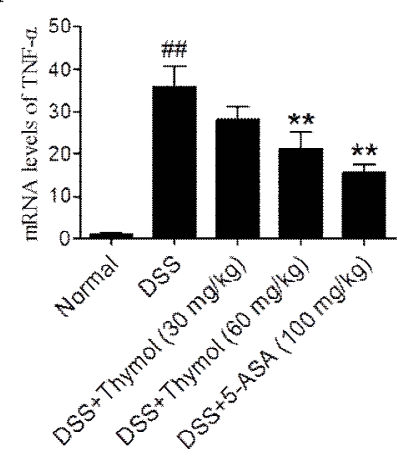

B

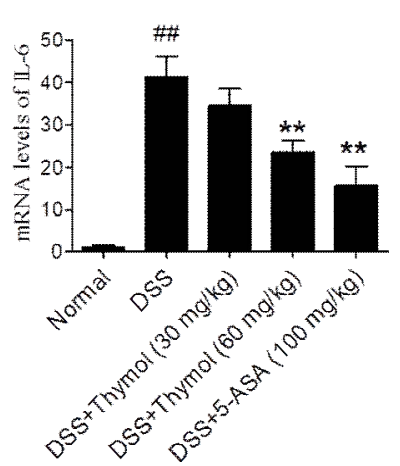

C

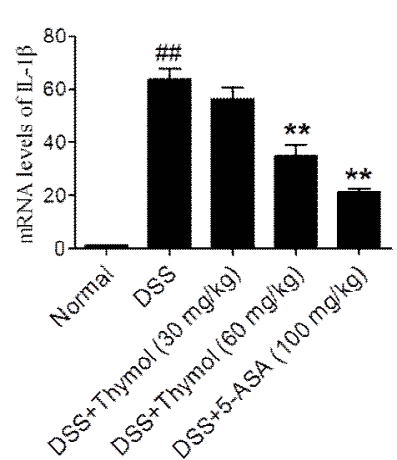

Figure 3: Effect of thymol on the production of pro-inflammation cytokines in colon tissues. The mRNA levels of (A) TNF- $\alpha,(B)$ IL- 6 and (C)IL-1 $\beta$ in colon tissues were assessed by real-time PCR $(n=6) .{ }^{\# \#} p<0.01$ vs normal, ${ }^{*} p<0.05,{ }^{* *} p<0.01$ vs DSS 
A

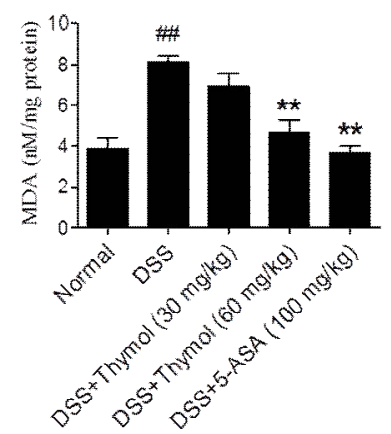

B

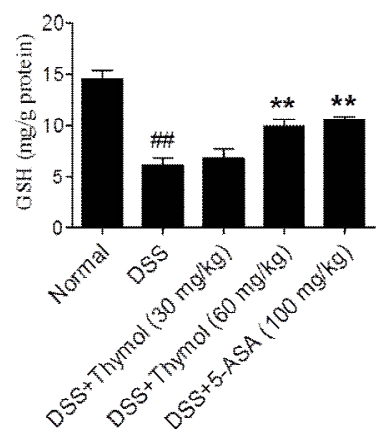

$\mathrm{C}$

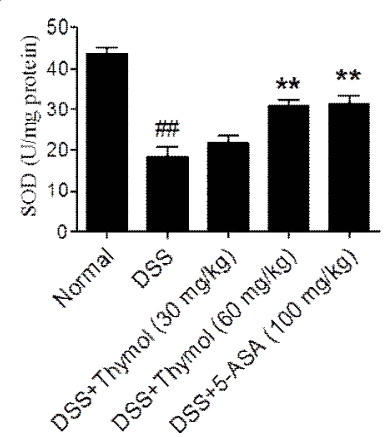

Figure 4: Effect of thymol on oxidative stress in colon tissues. The levels of (A) MDA, (B) GSH and(C) SOD in the colon tissues were measured by commercial kits $(n=6)$. ${ }^{\#} P<0.01$ vs normal, $p<0.05,{ }^{* *} p<0.01$ vs DSS

attenuated MDA level, improved levels of GSH and SOD in colon tissues (Figure 4A-C).

\section{Effect of thymol on the cell viability in macrophages}

Macrophages play key roles in the secretion of pro-inflammatory cytokines. Firstly, the effect of thymol on the cell viability in the presence or absence of LPS in RAW264.7 cells was investigated. Figure $5 \mathrm{~A}$ and $\mathrm{B}$ showed thymol had no significant cytotoxicity on RAW 264.7 cells at concentrations below $400 \mu \mathrm{M}$.
A

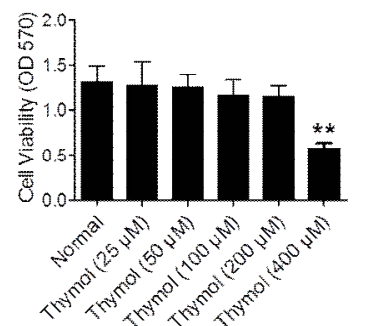

B

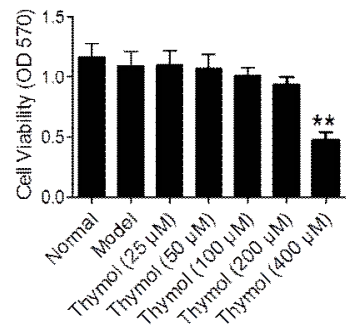

Figure 5: Effect of thymol on the cell viability in macrophages. Cell viability was determined by using MTT assay. RAW264.7 cells were treated with various concentrations of thymol $(25,50,100,200$ and 400 $\mu \mathrm{M})(\mathrm{A})$ in the absence or $(\mathrm{B})$ presence of LPS (1 $\mu \mathrm{g} / \mathrm{mL}$ ) for $24 \mathrm{~h}$. Data are representative of three independent experiments; ${ }^{* *} p<0.01$ vs normal

\section{Effect of thymol on levels of inflammatory mediators in LPS-induced macrophages}

The effect of thymol on the secretion of inflammatory mediators, such as NO, TNF- $\alpha$, IL6 and IL-1 $\beta$ in LPS-induced macrophages was evaluated. LPS stimulation markedly increased the production of NO, TNF- $\alpha, \mathrm{IL}-6$ and IL- $1 \beta$ in RAW264 cells. However, thymol (100 and 200 $\mu \mathrm{M})$ inhibited the LPS-induced increases in levels of NO, TNF- $\alpha$, IL- 6 and IL- $1 \beta$ in a concentration-dependent manner (Figure 6 A-D).
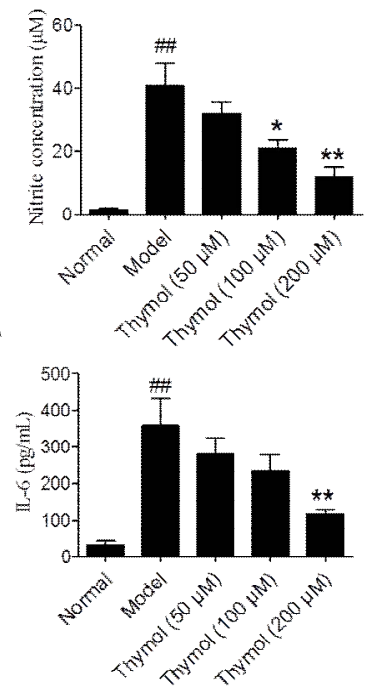

D

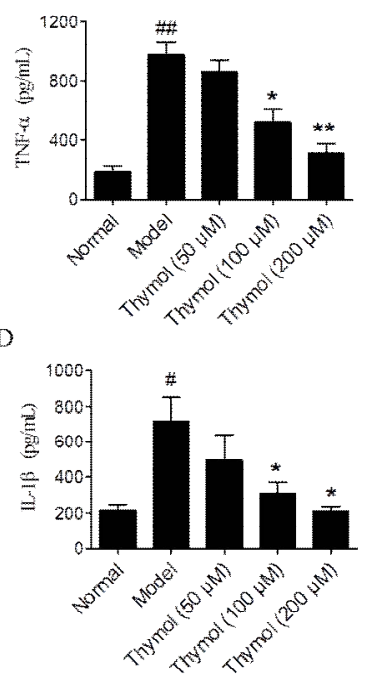

Figure 6: Effects of thymol on levels of inflammatory mediators in LPS-induced macrophages. RAW264.7 cells were cultured with thymol $(50,100$ and $200 \mu \mathrm{M})$ in the presence or absence of $1 \mu \mathrm{g} / \mathrm{mL}$ LPS. After treatment with $24 \mathrm{~h}$, the culture supernatants were collected. (A) NO level was measured by using Griess assay. The levels of (B) TNF- $\alpha,(C)$ IL- 6 and (D) IL-1 $\beta$ were determined by using ELISA kits. Data are representative of three independent experiments; ${ }^{\#} p<$ 0.01 vs normal, ${ }^{*} p<0.05,{ }^{* *} p<0.01$ vs model

\section{Effect of thymol on activation of NF-KB pathway in LPS-induced macrophages}

In general, LPS binds to toll-like receptors and activates many downstream signaling pathways, such as NF-KB pathway [18]. To address the mechanism for thymol inhibiting the levels of proinflammatory mediators, effect of thymol on the activation of NF-KB signaling by using Western blot was determined. Figure 7 showed that LPS treatment markedly increased the level of phosphorylation of $1 \mathrm{kBa}$ and NF-kB-p65 in RAW264.7 cells. Thymol treatment significantly down-regulated the activation of NF-KB signaling pathway. 


\section{DISCUSSION}

It is indispensable to optimize the therapeutic options for UC treatment. The present study aimed to find a potent drug candidate for the treatment of UC. The study report that thymol attenuates colitis induced by DSS in mice by inhibiting pro-inflammatory mediator production from macrophages via down-regulation of activation of NF-KB pathways.

In the clinic, UC is often associated with the goblet cell depletion, destruction of crypt architecture, inflammatory cells infiltration, and crypt inflammation [19]. In the results, thymol treatment inhibited inflammatory damage such as loss of goblet cell, mononuclear cell infiltration. The level of MPO indicated that infiltration of neutrophils in the colon tissues, and thymol showed a markedly reduction in MPO levels in the colon.

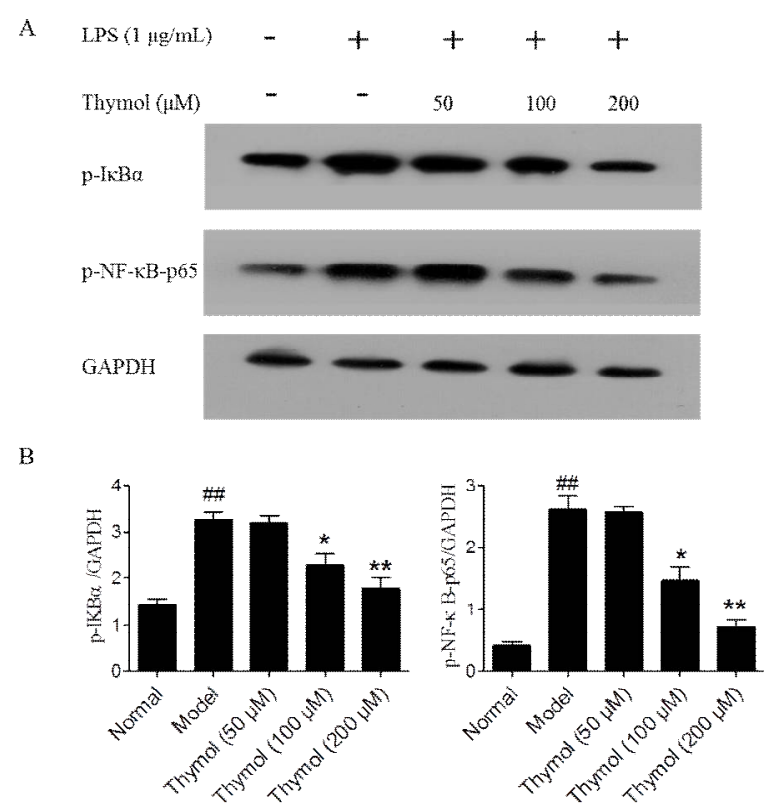

Figure 7: Effect of thymol on activation of NF-kB pathway in LPS-induced macrophages. RAW264.7 cells were pre-treated with thymol (50, 100 and 200 $\mu \mathrm{M})$ for $20 \mathrm{~h}$, then stimulated with LPS $(1 \mu \mathrm{g} / \mathrm{mL})$ for $30 \mathrm{~min}$. Total protein were extracted. (A) Levels of $p$ IkBa, p-NF-kB-p65 and GAPDH were analyzed by using Western blot. (B) Band densitometry were analyzed, and the quantitative data were shown. Data were representative of three independent experiments; ${ }^{\# \#} p<0.01$ vs normal, ${ }^{*} p<0.05,{ }^{* \star} p<0.01$ vs model

Previous studies showed that overproduction of inflammatory mediators from macrophages, such as pro-inflammatory cytokines and reactive oxygen metabolites (e.g., NO), is mostly involved in the inflammation cascade reaction and subsequent colon damage in UC [20]. Macrophages secrete TNF- $\alpha$, IL- 6 and IL-1 $1 \beta$, which are considered as crucial inflammatory mediators. In the colon mucosa of patients with UC, their levels are markedly increased [21]. The results demonstrated that thymol inhibited production of pro-inflammatory mediators in the colons of colitis mice, as well as in LPSstimulated macrophages.

Previous studies showed that oxidative stress kept the inflammation response active in the colon mucosa. The lipid peroxidation product MDA cause tissue damage. In parallel, reduction of GSH and SOD, the main intracellular antioxidant, have been detected in the colonic mucosa of UC patients [22]. The results showed that treatment with DSS markedly reduced the levels of GSH and SOD, and enhanced MDA level in the colonic tissues, which is in consistent with the previous finding [23]. The results shows that thymol significantly suppressed oxidative stress induced by DSS.

LPS are recognized by mucosal macrophages via TLR4. Then macrophages have an elevated ability to produce TNF- $\alpha, \mathrm{IL}-6$ and IL- $1 \beta$, causing the activation of NF-KB [24]. Hence, it is speculated that the anti-inflammatory effect of thymol was due to the suppression of NF-KB pathway, regulating the expression of numerous inflammatory factors. The inducible form of NF$\mathrm{KB}$ is typically a heterodimer composed of a p50 and p65 subunits, present in cytoplasm as an inactive complex associated with inhibitory protein IKB. The activation of this complex by various stimuli lead to the phosphorylation, ubiquination and degradation of IKB proteins. Then, NF-kB heterodimer (p65/p50) will rapidly translocate into the nucleus, regulate the transcriptions of a large number of target genes, such as pro-inflammatory cytokines (TNF- $\alpha$, IL-6 and IL-1 $\beta$ ) $[25,26]$. Although thymol inhibited NFKB-p65 phosphorylation in mouse epithelial cells [27], the results demonstrated it can inhibit LPSinduced NF-kB activation in macrophages.

\section{CONCLUSION}

Thymol shows protective effects against DSSinduced colitis, and reduces the production of pro-inflammatory mediators and oxidative damage in colon tissues. The mechanism involves the inhibition of the NF-KB activation. Thus, thymol is a potential candidate drug for UC treatment.

\section{DECLARATIONS}

\section{Conflict of Interest}

No conflict of interest associated with this work. 


\section{Contribution of Authors}

We declare that this work was done by the authors named in this article and all liabilities pertaining to claims relating to the content of this article will be borne by the authors. De-Ming Liu and Wen Li conceived and designed the study; Ping Wang and Chun-Yan Zhou collected and analyzed the data; De-Ming Liu and Xian-Li Meng wrote the manuscript. All authors have read the manuscript and approved for publication.

\section{REFERENCES}

1. Ordas I, Eckmann L, Talamini M, Baumgart DC, Sandborn WJ. Ulcerative colitis. Lancet 2012; 380: 1606-1619.

2. Terzic J, Grivennikov S, Karin E, Karin M. Inflammation and colon cancer. Gastroenterol 2010; 138: 2101-2114 e2105.

3. Abraham C, Cho JH. Inflammatory bowel disease. $\mathrm{N}$ Engl J Med 2009; 361: 2066-2078.

4. Okayasu I, Hatakeyama S, Yamada M, Ohkusa T, Inagaki $Y$, Nakaya $R$. A novel method in the induction of reliable experimental acute and chronic ulcerative colitis in mice. Gastroenterol 1990; 98: 694-702.

5. Ho G-T, Lees C, Satsangi J. Ulcerative colitis. Medicine 2011; 39: 224-228.

6. van Dieren JM, Kuipers EJ, Samsom JN, Nieuwenhuis EE, van der Woude CJ. Revisiting the immunomodulators tacrolimus, methotrexate, and mycophenolate mofetil: their mechanisms of action and role in the treatment of IBD. Inflamm Bowel Dis 2006; 12: 311-327.

7. Saravanan S, Pari L. Protective effect of thymol on high fat diet induced diabetic nephropathy in C57BL/6J mice. Chem Biol Interact 2016; 245: 1-11.

8. Patil D, Dhaneshwar $S$, Kadam P. Diacerein-thymol prodrug: in vivo release and pharmacological screening in experimental models of osteoarthritis in Wistar rats. Inflamm Allergy Drug Targets 2015; 13: 393-405.

9. Zhou E, Fu Y, Wei Z, Yu Y, Zhang X, Yang Z. Thymol attenuates allergic airway inflammation in ovalbumin (OVA)-induced mouse asthma. Fitoterapia 2014; 96 : 131-137.

10. Miladi H, Zmantar T, Chaabouni Y, Fedhila K, Bakhrouf A, Mahdouani K, Chaieb K. Antibacterial and efflux pump inhibitors of thymol and carvacrol against foodborne pathogens. Microb Pathog 2016; 99: 95-100.

11. Fitsiou E, Anestopoulos I, Chlichlia K, Galanis A, Kourkoutas I, Panayiotidis MI, Pappa A. Antioxidant and antiproliferative properties of the essential oils of Satureja thymbra and Satureja parnassica and their major constituents. Anticancer Res 2016; 36: 57575763.

12. Amdekar $S$, Singh $V$, Singh $R$, Sharma $P$, Keshav $P$, Kumar A. Lactobacillus casei reduces the inflammatory joint damage associated with collagen-induced arthritis (CIA) by reducing the pro-inflammatory cytokines: Lactobacillus casei: COX-2 inhibitor. J Clin Immunol 201; 31: 147-154.

13. Wu X, Dou Y, Yang Y, Bian D, Luo J, Tong B, Xia Y, Dai $Y$. Arctigenin exerts anti-colitis efficacy through inhibiting the differentiation of Th1 and Th17 cells via an mTORC1-dependent pathway. Biochem Pharmacol 2015; 96: 323-336.

14. Tao F, Qian C, Guo W, Luo Q, Xu Q, Sun Y. Inhibition of Th1/Th17 responses via suppression of STAT1 and STAT3 activation contributes to the amelioration of murine experimental colitis by a natural flavonoid glucoside icariin. Biochem Pharmacol 2013; 85: 798807.

15. Park MY, Ji GE, Sung MK. Dietary kaempferol suppresses inflammation of dextran sulfate sodiuminduced colitis in mice. Dig Dis Sci 2012; 57: 355-363.

16. Zanoni I, Ostuni R, Marek LR, Barresi S, Barbalat $R$, Barton GM, Granucci F, Kagan JC. CD14 controls the LPS-induced endocytosis of Toll-like receptor 4. Cell 2011; 147: 868-880.

17. Luo J, Liu M, Wu X, Dou Y, Xia Y, Dai Y, Wei Z. DGAEE, a newly synthesized derivative of glycyrrhetinic acid, potently attenuates mouse septic shock via its main metabolite DGA in an IL-10-dependent manner. Int Immunopharmacol 2015; 29: 583-590.

18. Yamamoto M, Akira S. Lipid A receptor TLR4-mediated signaling pathways. Adv Exp Med Biol 2010; 667: 59-68.

19. Ho G-T, Lees C, Satsangi J. Ulcerative colitis. Medicine 2007; 35: 277-282.

20. Ogata H, Hibi T. Cytokine and anti-cytokine therapies for inflammatory bowel disease. Curr Pharm Des 2003; 9: 1107-1113

21. Ford AC, Sandborn WJ, Khan KJ, Hanauer SB, Talley NJ, Moayyedi P. Efficacy of biological therapies in inflammatory bowel disease: systematic review and meta-analysis. Am J Gastroenterol 2011; 106: 644-659, quiz 660.

22. Biasi F, Leonarduzzi G, Oteiza PI, Poli G. Inflammatory bowel disease: mechanisms, redox considerations, and therapeutic targets. Antioxid Redox Signal 2013; 19: 1711-1747.

23. Nishiyama Y, Kataoka T, Yamato K, Taguchi T, Yamaoka $K$. Suppression of dextran sulfate sodium-induced colitis in mice by radon inhalation. Mediators Inflamm 2012; 2012: 239617.

24. Maloy KJ, Powrie F. Intestinal homeostasis and its breakdown in inflammatory bowel disease. Nature 2011; 474: 298-306.

25. Cho EJ, Shin JS, Chung KS, Lee YS, Cho YW, Baek NI, Chung HG, Lee KT. Arvelexin inhibits colonic inflammation by suppression of NF-kappaB activation in dextran sulfate sodium-induced mice and TNF-alphainduced colonic epithelial cells. J Agric Food Chem 2012; 60: 7398-7407.

26. Chen HW, Kuo HT, Wang SJ, Lu TS, Yang RC. In vivo heat shock protein assembles with septic liver NF-

Trop J Pharm Res, September 2018; 17(9): 1809 
kappaB/I-kappaB complex regulating NF-kappaB activity. Shock 2005; 24: 232-238.

27. Liang D, Li F, Fu Y, Cao Y, Song $X$, Wang $T$, Wang W, Guo M, Zhou E, Li D, et al. Thymol inhibits LPS - stimulated inflammatory response via down-regulation of NF-kappaB and MAPK signaling pathways in mouse mammary epithelial cells. Inflammation 2014; 37: 214222. 